$\mathrm{Oz}$

Volume 30

Article 4

$1-1-2008$

\title{
An Architecture of Poetic Realism
}

Sebastian Schmaling

Follow this and additional works at: https://newprairiepress.org/oz

(c) $($ ) $\Theta \Theta$

This work is licensed under a Creative Commons Attribution-Noncommercial-No Derivative Works 4.0 License.

\section{Recommended Citation}

Schmaling, Sebastian (2008) "An Architecture of Poetic Realism," Oz: Vol. 30. https://doi.org/10.4148/ 2378-5853.1453

This Article is brought to you for free and open access by New Prairie Press. It has been accepted for inclusion in Oz by an authorized administrator of New Prairie Press. For more information, please contact cads@k-state.edu. 


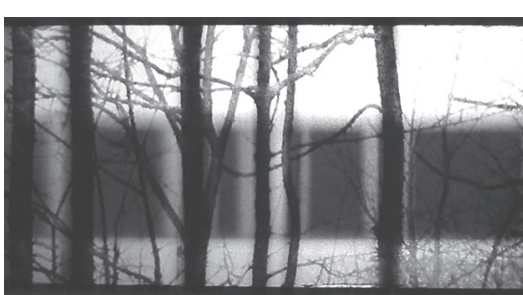

At a time when the global design avant garde is infatuated with the possibilities of algorithmic form-making, when "retinal-based architecture" 1 is a logical by-product of contemporary culture's opticentricity, and when virtual reality increasingly seems to trump actuality, our interest in hapticity, temporality, and architectural phenomenology may appear slightly archaic and out of step with contemporary thought.

Categorizing architects is a dangerously simplistic sport, and we have always been apprehensive of any of the various explicit or implicit labelsmodernists, minimalists, contextualists, regionalists-that our critics have assigned us, which tend to reveal more about a particular commentator's own bias than about our work. Our sensory experiences and atmospheric memories play a tremendously important role in the conceptual development of our projects, but does that make us phenomenologists? We are certainly not interested in rehearsing the decades-old arguments from phenomenological heavyweights such as Christian Norberg-Schulz, Maurice Merleau-Ponty, or Edmund Husserl, and our design process arguably differs from that of other contemporary practitioners such as Steven Holl, whose

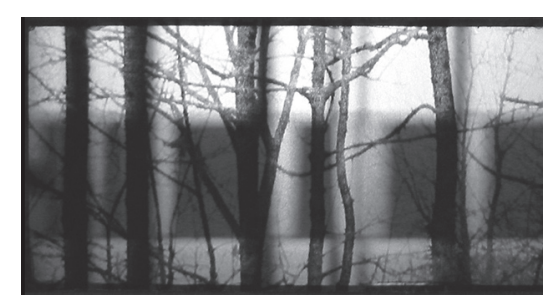

well-documented and who has argued that "to open architecture to questions of perception, we must...disengage the rational half of our mind."

Of course, Holl's position reverberates architecture's long struggle to transcend the rationalist formalism of orthodox modernism whose protagonists were arguably more interested in conceptual abstraction than individual

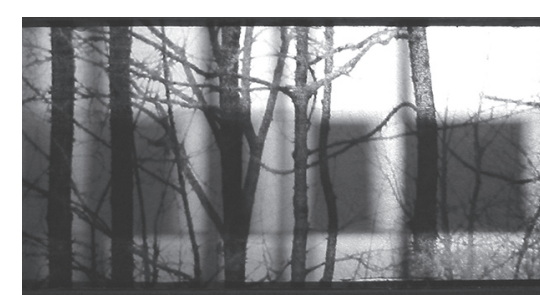

sensibilities. What concerns us about Holl's proposed partial lobotomy, however, is that, in the last decade or so, it has served as a blank check for an out-of-control architectural formalism whose suspension of basic laws of physic aptly mirrored-and, more importantly, was financed by-the Greenspanian "irrational exuberance" of the stock market. ${ }^{3}$ What we fail to see is why rationality, especially as it concerns program, structure, and ultimately, form, should be castigated as inevitably antagonistic to an architecture concerned with human intuition and perception. After all, when even the popular (though involuntary) poster boys of rationalism and phenomenology, Ludwig Mies van der Rohe and Martin Heidegger, turn out not to be the philosophical polar opposites that mainstream academia has made us believe, as Rebecca Comway successfully argues, it becomes apparent that a sober design language and sensuous design strategies are not mutually exclusive. ${ }^{4}$ Instead, it seems to us that the exact opposite is true: that architectural richness can only be achieved when, in the words of Peter

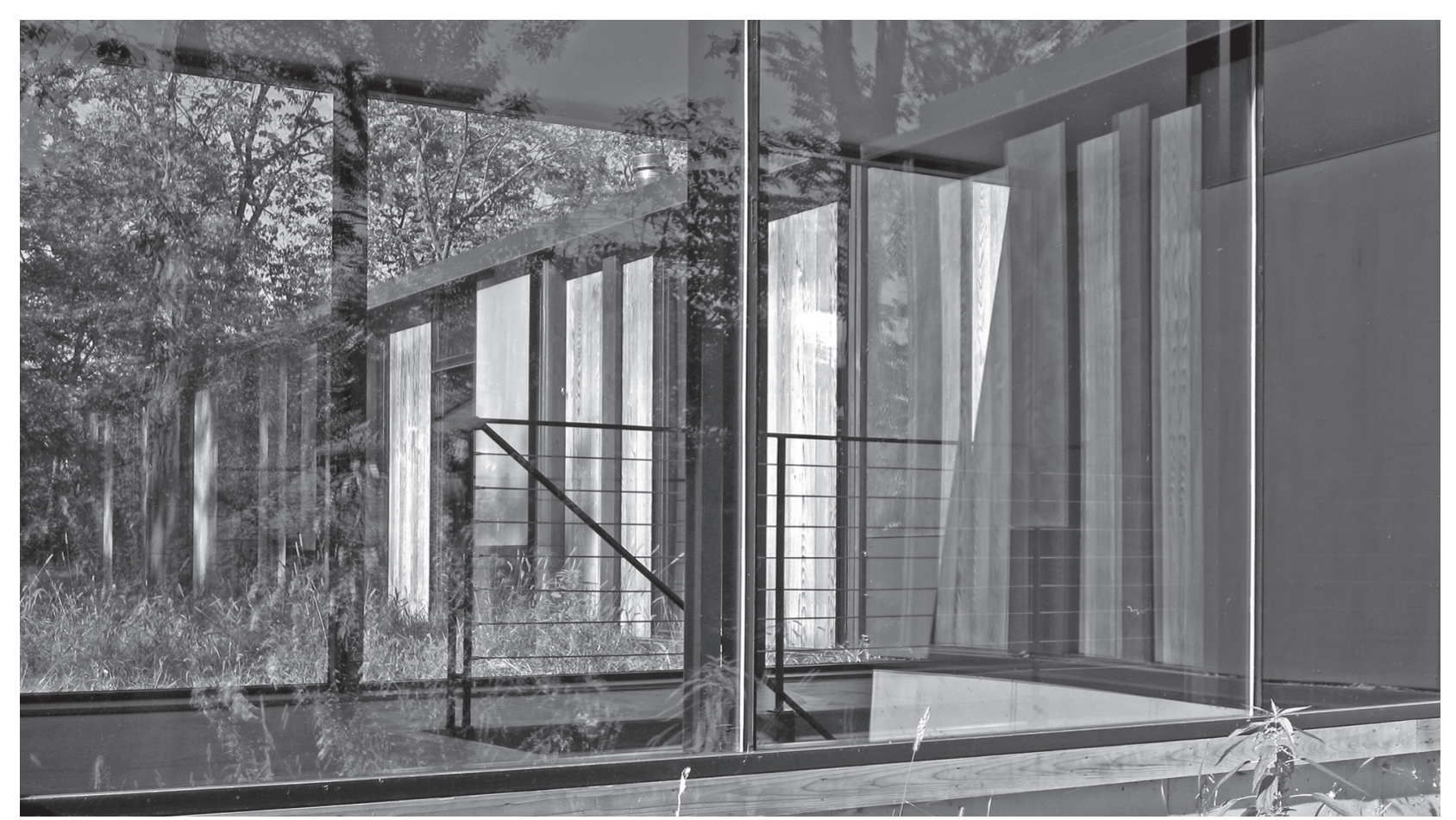


Zumthor, there is a "constant interplay of feeling and reason."

We are a young office with a limited body of work, and we certainly do not want to suggest that we can offer a universally applicable recipe for a successful marriage between formal purity and compositional rigor on one side and experiential vigor on the other. But one of our recent projects, Camouflage House, may serve as a case study for what we call an architecture of poetic realism-an architecture based on a subjective reading of site and context but formally constrained by the realities of topography, labor skills, available materials, and budgetary restrictions. An architecture of poetic realism - "an

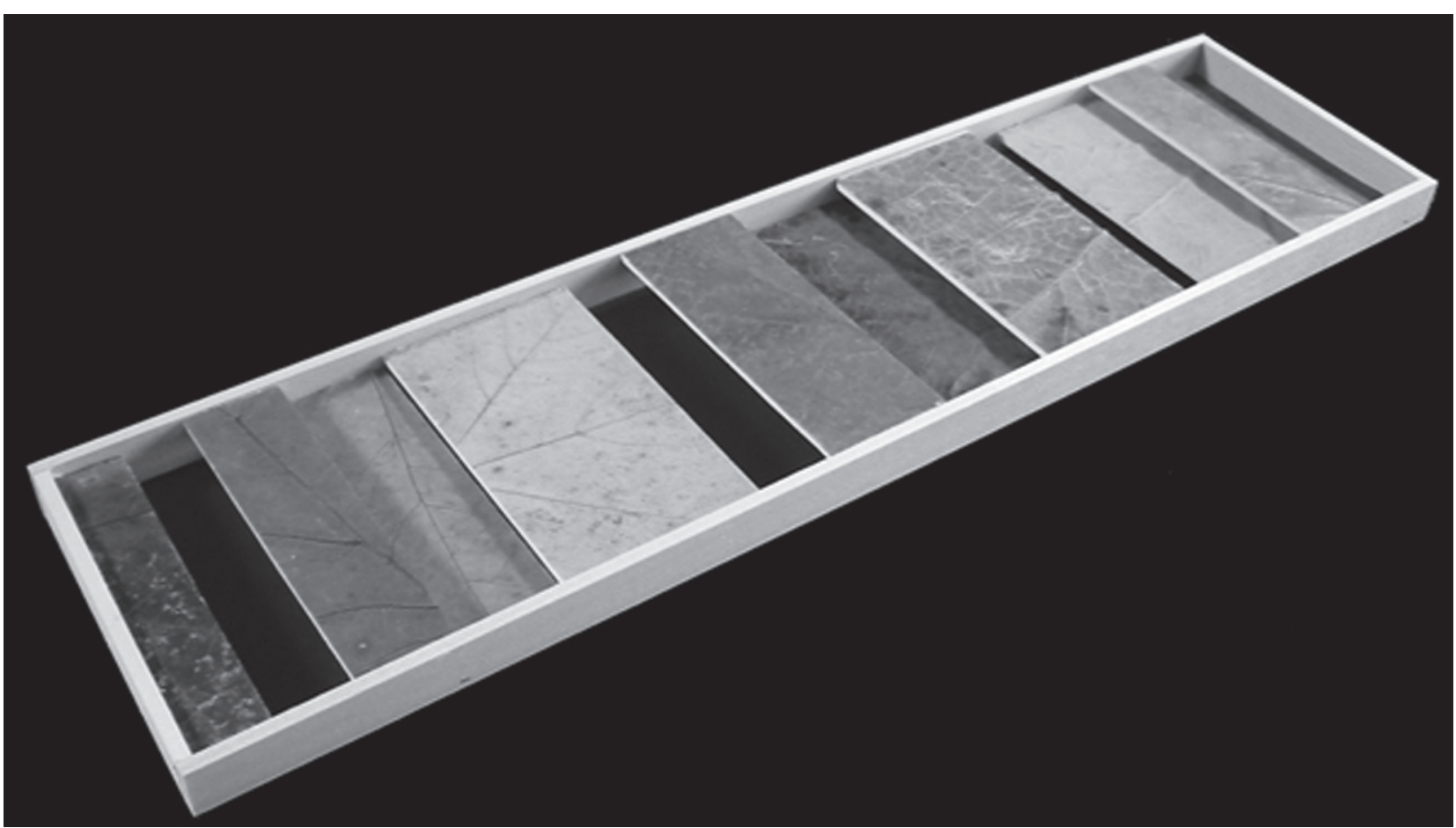

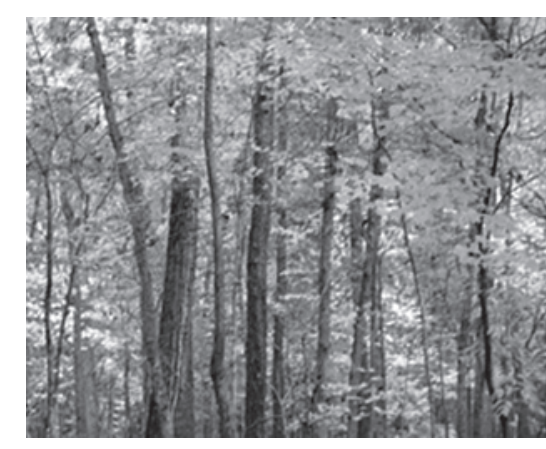

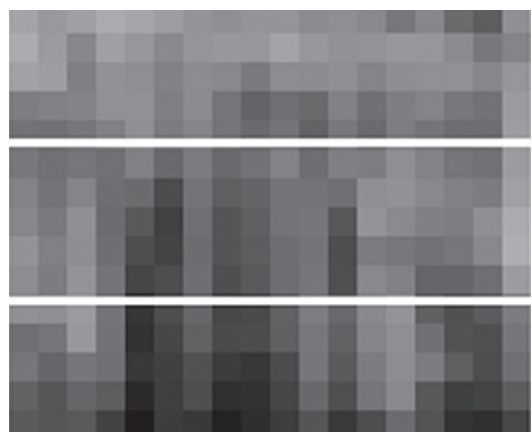

|IIIIII||

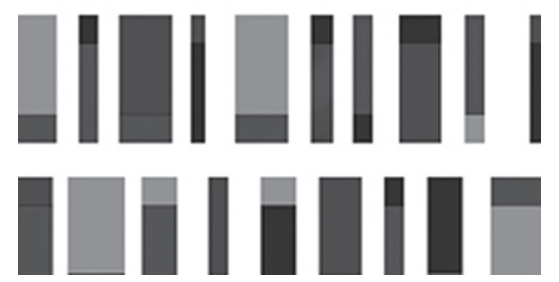

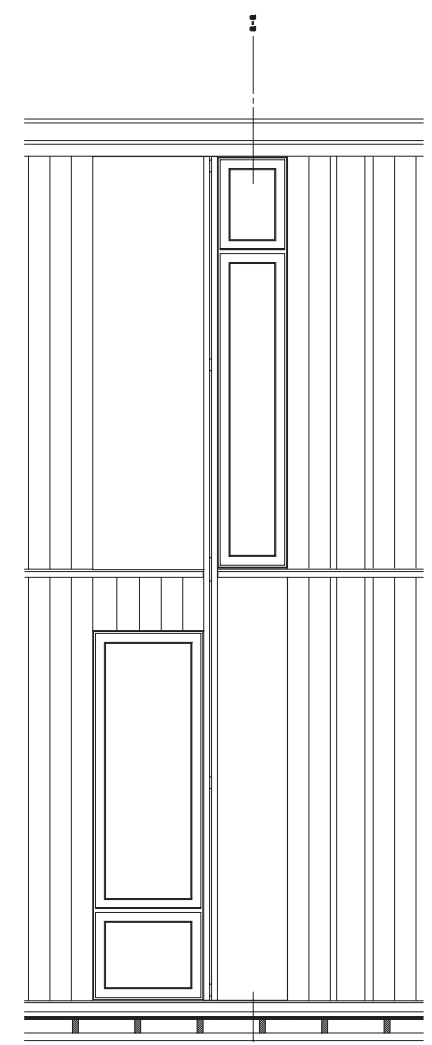



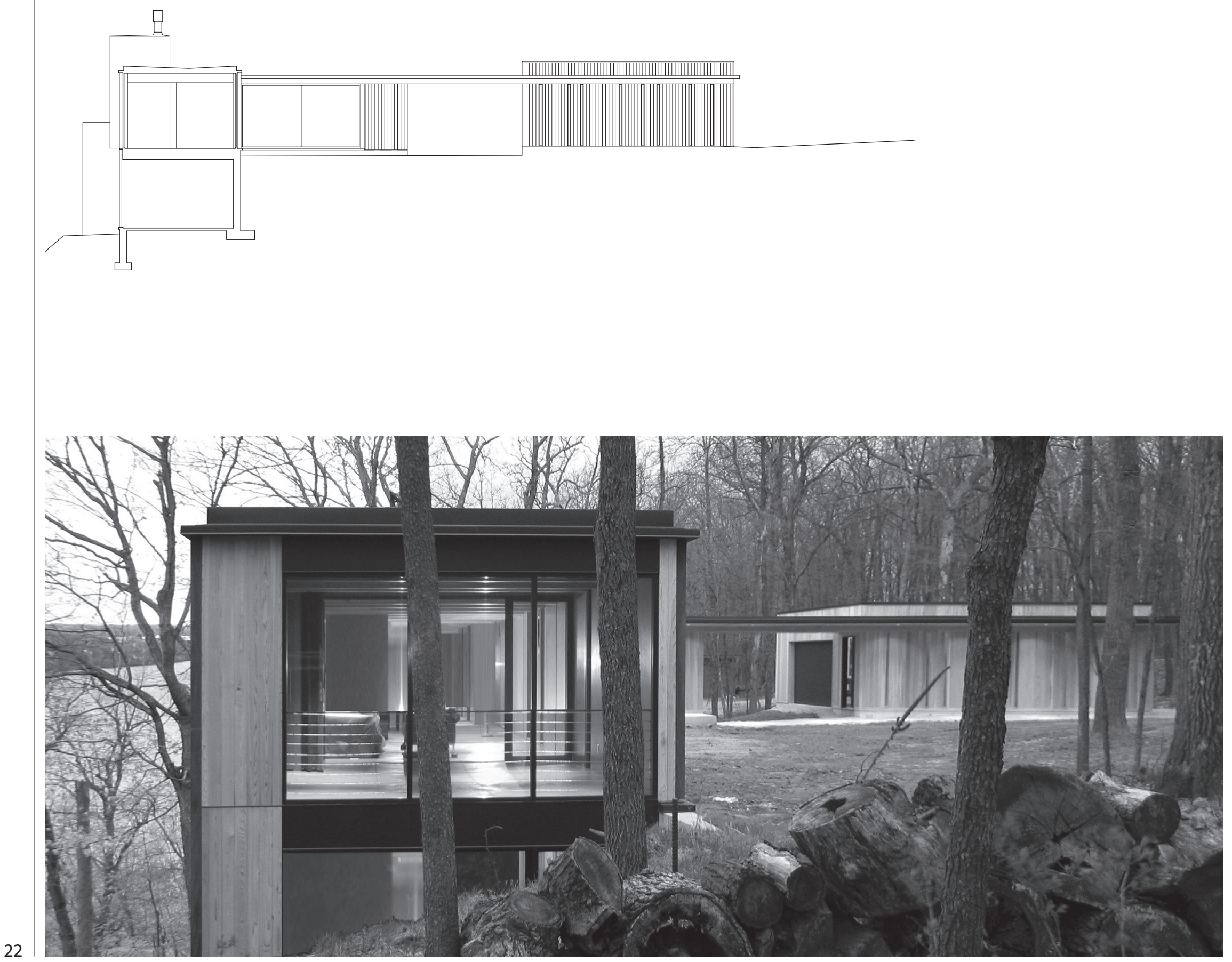
architecture of melancholic silence and intense restraint," as Rodolfo Machado described our work in a recent exhibition catalogue 6 -imbues a building with an aura inspired by our subjective and purposefully selective recollection, or, to use a Heideggerian term, Andenken, of a particular locale's most striking characteristics, both physical, atmospheric, and social, while staying within the realm of constructability and functional logic. This is impossible to achieve without a sound understanding of building systems, structural principles, and material properties. More importantly, however, it requires a level of humility vis-à-vis your surroundings, a willingness to accept what already exists, and the suspension of the modernist ur-belief that a heroic and increasingly dematerialized and antiseptic architecture could domesticate a messy world.

Indeed, the feeling of humility was unavoidable when we first visited the site for the Camouflage House, a beautiful, heavily wooded bluff overlooking Wisconsin's Green Lake. "Isn't it brazen," we asked ourselves, "to build a structure in this context, permanently leaving human marks on the virgin soil?" It became immediately apparent that the design needed to be submissive to its surroundings and able to assimilate with it, subtly echoing its context rather than imposing itself upon it-in other words, a design inspired by our reading of the terrain and its sometimes ethereal characteristics rather than by a preconceived set of compositional formulas and aesthetic rules, perhaps following the conceptual trajectory of Ignasi de Solà-Morales's notion of "weak architecture."?

Our client was in no rush, so we had the luxury of visiting the site throughout the year, walking through the forest, documenting spatial relationships, mapping topographic features like rock outcroppings and clusters of old trees, and watching the sun rise over the lake, circle across the sky, and disappear early behind the impenetrable foliage.

What left lasting impressions and played a critical role in the conceptual development of the Camouflage House were the trees' arresting verticality and the rhythmic shifts between the trunks as we moved through the site, creating a complex matrix of lines and

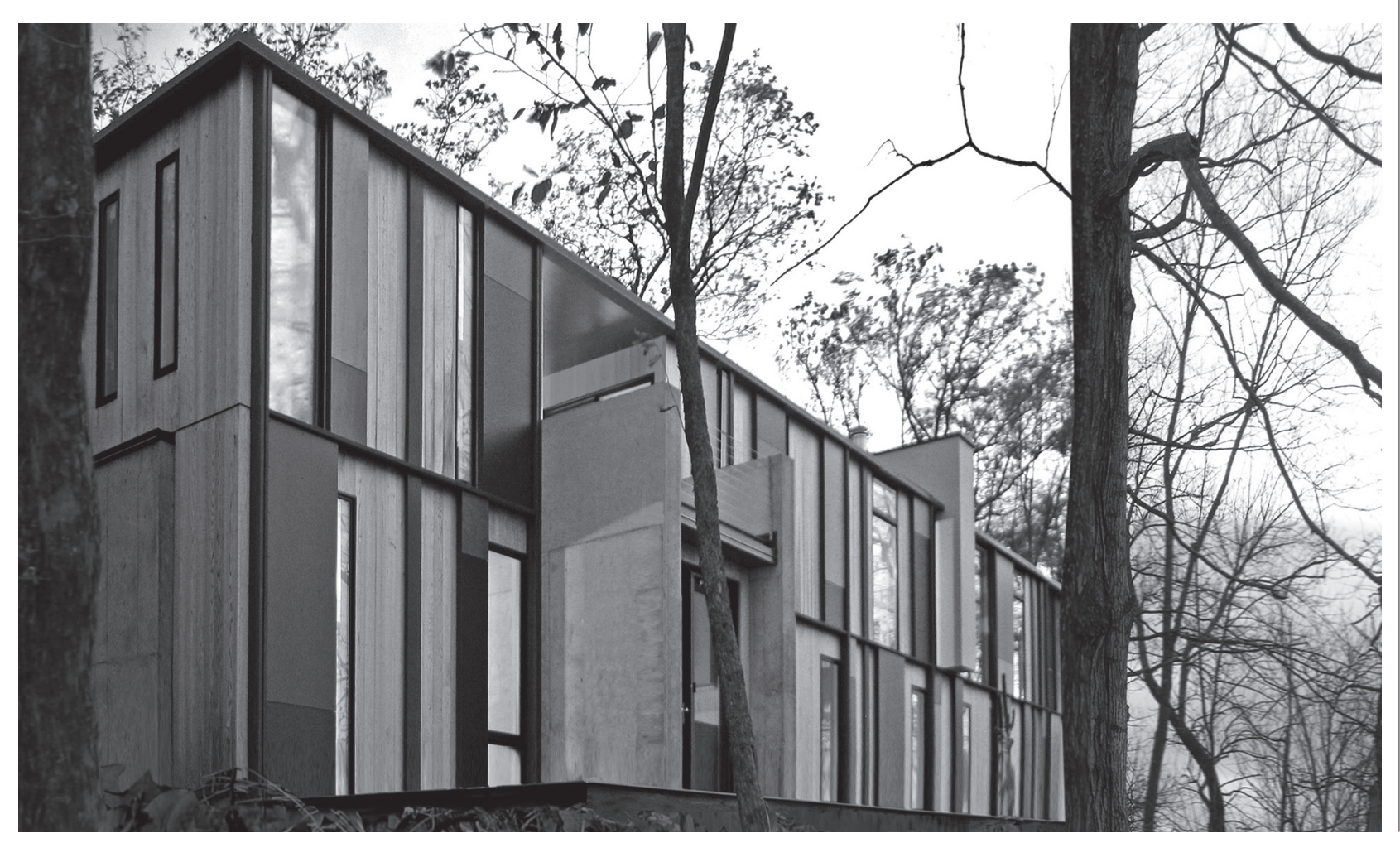


distorting our perception of space and scale. We tested different strategies to translate this phenomenon into an abstract architectonic device, using collages and a series of shadow boxes to experiment how patterns of solids and voids could be juxtaposed to reverberate the forest's rhythmic laminations.

The character of the site went through a dramatic metamorphosis as we returned throughout the year. The trees changed their color from light green in the spring to the fall's boundless shades of red, yellow, and brown before falling dormant in November, washing the site in an ominous monochrome of black and grey. We collected leaves and chunks of bark and explored in a series of study models how their colors and textures could inform the skin of the house. We incrementally pixellated images of the site's flora to develop a system of façade components that would eventually create a "fatigue" for the house, a veil wrapping around the house and camouflaging its body.

Throughout these investigations, it became clear that the building itself needed to be a simple volume, creating a regular base line, a structural metronome against which the complex system of shifting solids and voidswall and glass panels-would become legible. After carefully choreographing the approach to the house on the rugged access road weaving through the heavily wooded plateau, we determined the final position of the house and studied possible massing alterna- volume nestled into the hillside. Its faint, low-slung silhouette virtually disappeared into the thick vegetation until you arrive at the small clearing of the entry court.

The house itself is an exposed postand-beam structure strictly following a 48-inch base grid, allowing us to organize the program efficiently while taking advantage of a cost-effective construction typology familiar to the rural craftsmen involved in the project. Informed by our early conceptual studies, we superimposed a complex system of facade layers over the building's structural skeleton. The first layer is a thin skin of untreated vertical cedar boards; it serves as the backdrop for a series of polychromatic Prodema wood veneer panels that resonate the ever-changing hues of the surrounding deciduous tress. The panels, their placement determined by a small number of regulated modules, are held off 6 inches from the cedar wall but sit back from the exposed edges of the exposed structural columns, thus creating a subtly undulating façade that softens the boundaries between building and context and casts deep shadows onto itself. Over time, the cedar wall, with all its natural imperfections and tactility, will weather to a silver gray, matching the color and visual depth of bark. The smooth, resinbased Prodema panels, on the other hand, will retain their original color and pristine finish, setting up an interesting interplay between temporality and eternity, between the material and immaterial. ${ }^{8}$ As it ages, the house will slowly vanish into the landscape, but the mysteriously ageless colored panels will continue to float on the horizon.

Floor-to-ceiling windows, their proportions matching those of the veneer panels, perforate the building volume Instead of following predetermined

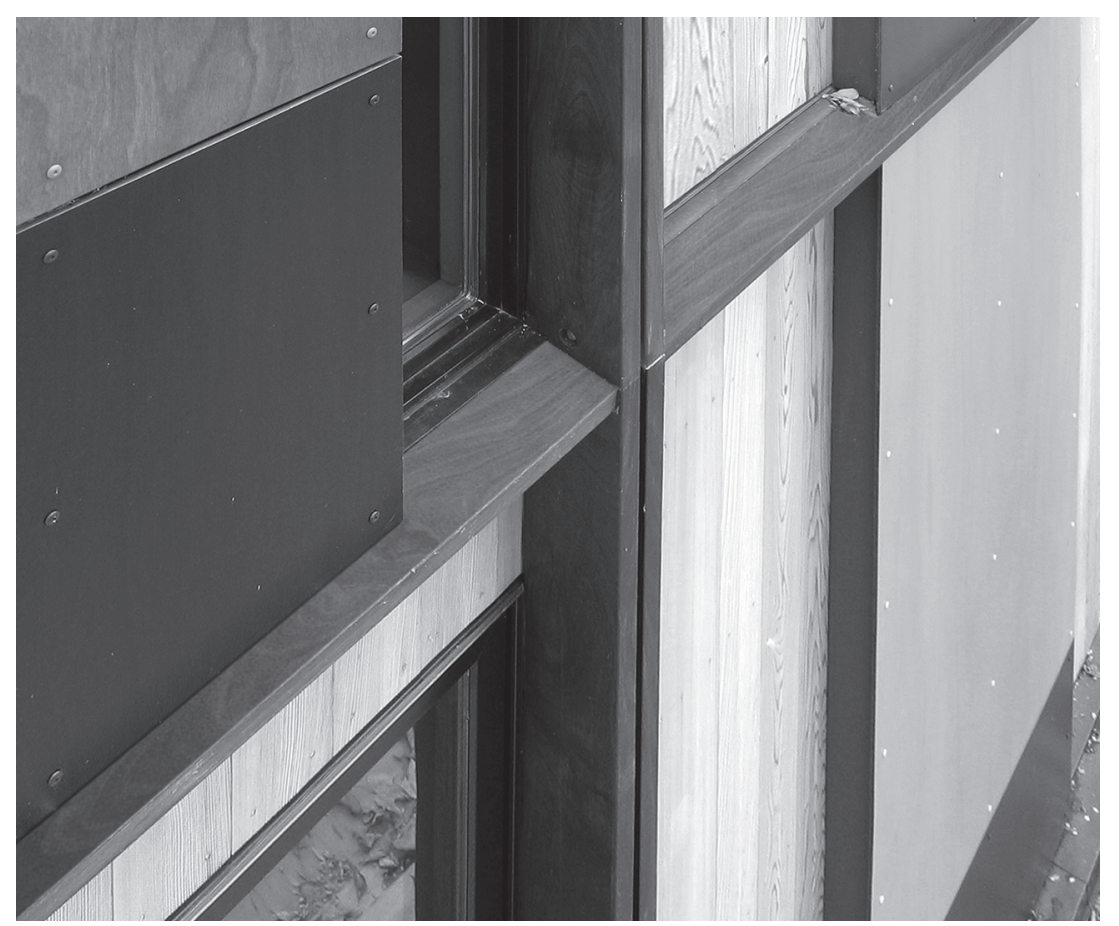


compositional rules, we positioned the window panels wherever they could capture important views into the site, frame particular trees, and facilitate different interior light qualities throughout the day. The resulting asymmetrical window distribution complements the juxtaposition of wall panels and structural grid, creating a controlled randomness that abstractly emulates the visual complexities of the surrounding forest. As you approach the building, the window shifts open and obscure through the building and toward the lake, depending on your position. At night, the strips of glass turn into a series of vertical lights emitting an enigmatic glow into the site.

We have been criticized that the design of the Camouflage House is based on a narrative informed by a very subjective set of experiences, but that criticism of subjectivity completely misses the point of poetic realism. Contextuality will always depend on the observer's perspective and manifests itself in many different ways. We certainly don't believe that architecture can transcend the banality and universal homegeneity of today's commodified modernism through Gehryesque volumetric fireworks or the computer-generated illusion of formal individualism. Instead, we need to renew our confidence in the ability to see, feel, and taste our surroundings and, through the metabolism of design, translate those senses, emotions, and poetic qualities into a meaningful palette of architectural operations.

\section{Notes}

I borrowed this term from Juhani Pallasmaa's excellent article "Hapticity and Time. Notes on Fragile Architecture," Architectural Review 207, no. 1239 (March 2000): 78-83

${ }^{2}$ See Steven Holl, Juhani Pallasmaa, and Alberto Perez-Gomez, Questions of Perception: Phenomenology in Architecture (San Francisco: William Stout, 2007). The original texts were published in 1997 in an $A+U$ special edition.

${ }^{3}$ It will be interesting to see if the current economic downturn and the tightening credit markets will require a new architectural diet: a low-carb regimen for leaner buildings in lieu of the formalistic fireworks of a design profession on steroids that may simply be too expensive to sustain.

${ }^{4}$ See Rebecca Comway, "Almost Nothing. Heidegger and Mies," in The Presence of Mies, edited by Detlef Mertins (New York: Princeton Architectural Press, 1994), 179-189.

Peter Zumthor, Thinking Architecture (Basel: Birkhauser, 1998), 20.

"Rodolfo Machado, "Melancholic Silence, Intense Restraint" in the exhibition catalog Johnsen Schmaling Architects-Extending the Surface (I Space Gallery, University of Illinois, 2005), 4-5.

"See Ignasi de Solà-Morales, "Arquitectura dédil” [Weak Architecture], in Differences: Topographies of Contemporary Architecture; ed. Sarah Whiting, trans. Graham Thompson (Cambridge: MIT Press, 1996).

${ }^{8}$ In his review of the Camouflage House in Metropolis, Edward Keegan focused on this tension between the material and the immaterial: "The idea of camouflage is based on deception: the success of the house lies in its ability to disappear into its setting as well as an object in its own right. The paradoxical nature of 'building the immaterial' is reflected in the architect's choice of materials. For all the apparent naturalness of the house, it's a metaphor rather than an assembly of truly natural components." Edward Keegan, "Into the Woods," Metropolis (May 2007): 148-151, 203.

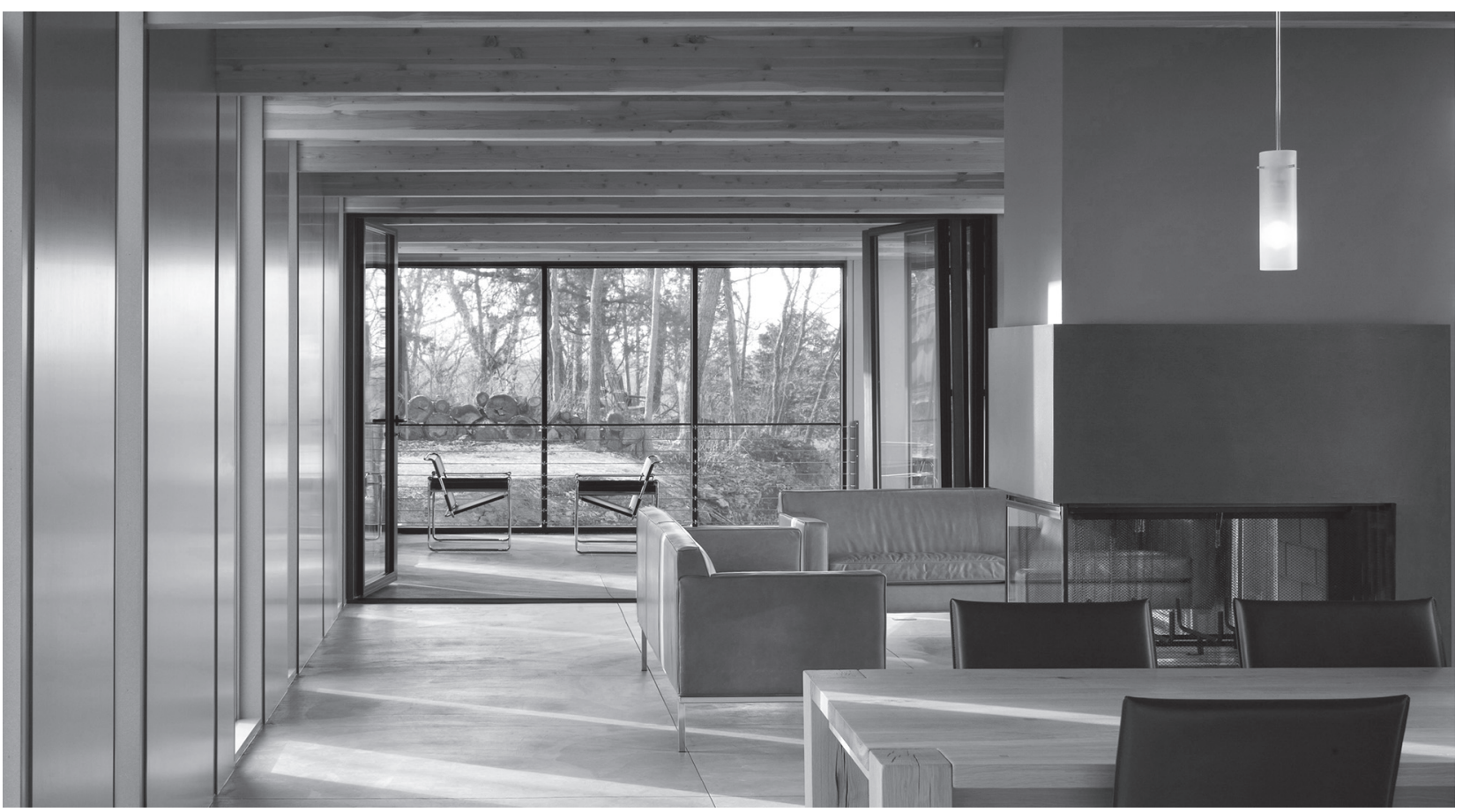

